\title{
Medidas de Mobilidade Urbana Sustentável (MMUS): propostas para o licenciamento de Polos Geradores De Viagens
}

\author{
Denise Vaz de Carvalho Santos ${ }^{1}$, Ilce Marilia Dantas Pinto de Freitas²
}

\begin{abstract}
Trip Generators are known to produce many trips by car and to contribute to the unsustainable mobility in cities. Current processes for licensing those developments reinforce negative impacts caused by these buildings by making several requirements to support car trips while treats too briefly the public and non-motorized modes, which should be a priority. This paper presents a set of 37 Measures of Sustainable Urban Mobility (MSUM), that can be applied in the licensing processes of large developments, and their validation by experts. The validation of the MSUM was made through an online survey with practitioners and researchers. The results demonstrate broad acceptance of the proposed measures and reveal a strong importance given to the subject.
\end{abstract}

Keywords: Sustainable Urban Mobility. Development Permit. Trip Generators.

Resumo: Polos Geradores de Viagens (PGV) são conhecidos por produzir muitas viagens por automóvel e por contribuírem para a mobilidade insustentável nas cidades. Os processos atuais para o licenciamento de PGVs, inclusive, reforçam os impactos negativos provocados por estes empreendimentos ao fazerem diversas exigências de suporte às viagens por automóveis enquanto tratam sumariamente as viagens por modos públicos e não motorizados, que deveriam ser prioritárias. Neste artigo apresenta-se um conjunto de 37 Medidas de Mobilidade Urbana Sustentável (MMUS), passíveis de aplicação em processos de licenciamento de grandes empreendimentos, e sua validação por especialistas. O método de validação das MMUS se deu através de pesquisa de opinião com profissionais e acadêmicos, por questionário online. Os resultados demonstram ampla aceitação das medidas propostas e revelam uma grande importância atribuída ao tema.

Palavras-chave: Mobilidade Urbana Sustentável. Licenciamento. Polos Geradores de Viagens.

\section{INTRODUÇÃO}

Polos Geradores de Viagens (PGV), originalmente denominados Polos Geradores de Tráfego (PGT), são "locais ou empreendimentos de distintas naturezas que tem em comum o desenvolvimento de atividades em porte e escala capazes de exercer grande atratividade sobre a população, produzir um contingente significativo de viagens, necessitar de grandes espaços para estacionamento, cargas e descargas de bens, e embarque e desembarque de pessoas" (Rede PGV, 2014). Apesar de serem capazes de gerar impactos positivos, como o desenvolvimento e valorização de uma região, eles permanecem tradicionalmente associados a reflexos negativos sobre a estrutura viária, os sistemas de transporte e a mobilidade urbana.

Tanto na concepção arquitetônica de novos empreendimentos quanto nas demandas dos processos de licenciamento para sua aprovação municipal, o foco atual dos critérios para o desenvolvimento e aceitação de projetos é que eles atendam às demandas do transporte motorizado.

\footnotetext{
1 Universidade Federal da Bahia (denisevaz@gmail.com).

2 Universidade Federal da Bahia (ilce_marilia@hotmail.com).
}

Manuscrito recebido em 10/05/2013 e aprovado para publicação em 11/05/2014. Este artigo é parte de TRANSPORTES v. 22, n. 2, 2014. ISSN: 2237-1346 (online).

DOI: http://dx.doi.org/10.14295/transportes.v22i2.689
Tal postura, adotada por empreendedores e amparada pela administração pública, contraria os princípios e as diretrizes da Política Nacional de Mobilidade Urbana Sustentável (PNMUS) e da Lei que a institui (Lei $\mathrm{n}^{\circ} 12.587 / 2012$ ), como evidenciam os destaques a seguir:

Art. $5^{\circ}$ A Política Nacional de Mobilidade Urbana está fundamentada nos seguintes princípios: II - desenvolvimento sustentável das cidades, nas dimensões socioeconômicas e ambientais; VII - justa distribuição dos benefícios e ônus decorrentes do uso dos diferentes modos e serviços; VIII - equidade no uso do espaço público de circulação, vias e logradouros (...)

Art. $6^{\circ}$ A Política Nacional de Mobilidade Urbana é orientada pelas seguintes diretrizes: II prioridade dos modos de transportes não motorizados sobre os motorizados e dos serviços de transporte público coletivo sobre o transporte individual motorizado (...) (Lei $\mathrm{n}^{\circ}$ 12.587/2012).

Até mesmo quando o licenciamento requer um Estudo prévio de Impacto de Vizinhança (EIV), que deveria oferecer uma visão holística e integrada sobre os impactos urbanos, dificilmente as apreciações de projetos ultrapassam a barreira 
do mínimo requisitado no que tange à mobilidade.

Marques (2010) e Moreira (1997) constatam que poucos são os relatórios de Estudos de Impacto de Vizinhança que apresentam uma análise da mobilidade urbana incluindo todos os atores que ela compreende: o pedestre, o ciclista, o portador de necessidades especiais, o usuário de transporte público e, não mais importante, o usuário de automóvel particular. Ainda mais excepcionais são as análises que compreendem a integração dos modos ou a interação entre mobilidade e uso do solo - que é o "nó" conceitual onde os Polos Geradores de Viagens, afinal, se encontram. A partir desta constatação, pode-se ponderar que há um distanciamento indevido entre os campos da mobilidade urbana sustentável e das metodologias de análise e licenciamento de Polos Geradores de Viagens. No entanto, é fundamental reforçar essa relação, pois se os PGVs são corresponsáveis pela situação crítica a que chegou o trânsito urbano, devem ser eles também corresponsáveis por auxiliar no caminho inverso, promovendo o uso de modos mais sustentáveis de se deslocar pela cidade, contribuindo para tornar as áreas urbanas ambientalmente e socialmente mais equilibradas.

O objetivo desta pesquisa é, portanto, apresentar um conjunto de 37 de Medidas de Mobilidade Urbana Sustentável (MMUS) passíveis de incorporação em processos de licenciamento de PGVs de forma a contribuir para a promoção da Mobilidade Urbana Sustentável (MUS). As medidas foram propostas a partir da PNMUS, de trabalhos acadêmicos e da análise de relatórios de licenciamento. A metodologia adotada baseia-se em pesquisa de opinião com especialistas, para a qual utilizou-se um sistema gratuito de questionário online - o Google Spreadsheet - que, além de gráficos automáticos das respostas, fornece uma planilha completa dos dados para processamentos posteriores mais apurados ou condicionados. Neste ponto, deseja-se ressaltar as vantagens da utilização desse tipo de sistema para pesquisas de opinião de caráter abrangente, prático e rápido. No caso desta pesquisa foram obtidas 30 respostas de questionários aplicados com especialistas de todo o Brasil em um período de quinze dias. O processamento das informações e criação dos gráficos se iniciou imediatamente após a conclusão e exportação da planilha, evitando-se assim a inconveniente fase de digitalização de respostas.

Além do resultado eficiente obtido a partir da metodologia de validação adotada, com fácil replicação, o valor desta pesquisa se encontra, sobretudo, no produto de direta aplicação prática: um primeiro conjunto de MMUS para orientar os critérios de aprovação de empreendimentos em processos de licenciamento. Esta pesquisa também se apresenta relevante sob o ponto de vista científico, como potencial campo de estudo para estimular novas pesquisas que possam contribuir para a elaboração de projetos de PGVs voltados à qualidade de vida e ao desenvolvimento de cidades mais sustentáveis e saudáveis.

\section{APRECIAÇÃO DE PROJETOS PARA O LICENCIAMENTO DE PGVS}

Nos últimos anos tem-se percebido um grande esforço no desenvolvimento de novas abordagens e metodologias para a avaliação de impacto de PGVs com foco na sustentabilidade, especialmente dentre as pesquisas fomentadas pela Rede PGV (2014). Contudo, quando se trata de práticas municipais de apreciação de projetos para o licenciamento de empreendimentos, muitas metodologias sul americanas ainda estão focadas na estrutura viária para acesso de automóveis particulares e de carga e no quantitativo das vagas de estacionamentos, deixando em segundo plano ou mesmo ignorando quaisquer soluções que facilitariam a mobilidade de pedestres e ciclistas ou o acesso dos cidadãos ao transporte público coletivo no entorno dos empreendimentos.

Em textos que orientam a apreciação de projetos de PGVs no Brasil e em alguns países da América Latina o termo pedestre aparece quase sempre relacionado ao acesso ao interior da edificação ou às zonas de conflito dos pedestres com os veículos - como as travessias dos acessos. Nestes documentos, referências aos ciclistas muitas vezes sequer aparecem. Apesar de ser evidente que para a mobilidade das bicicletas exista a necessidade de implantação de rotas cicláveis (ciclovias ou ciclofaixas) e de equipamentos para a guarda das bicicletas, tais como paraciclos ou bicicletários, na prática isto não parece estar tão claro.

Para explicitar visualmente critérios de aprovação municipal de empreendimentos, a Figura 1 resume, de forma gráfica, a frequência de aparecimento de termos no conteúdo de documentos para o licenciamento de algumas cidades brasileiras e da América do Sul descritas em San- 
tos (2011). Vê-se que veículos e vagas ainda são os termos mais recorrentes. Logo, não é sem razão que tantos diagnósticos gerem resultados in- satisfatórios em relação à mobilidade urbana sustentável, como já sinalizavam Moreira (1997), Moraes (2008) e Marques (2010).

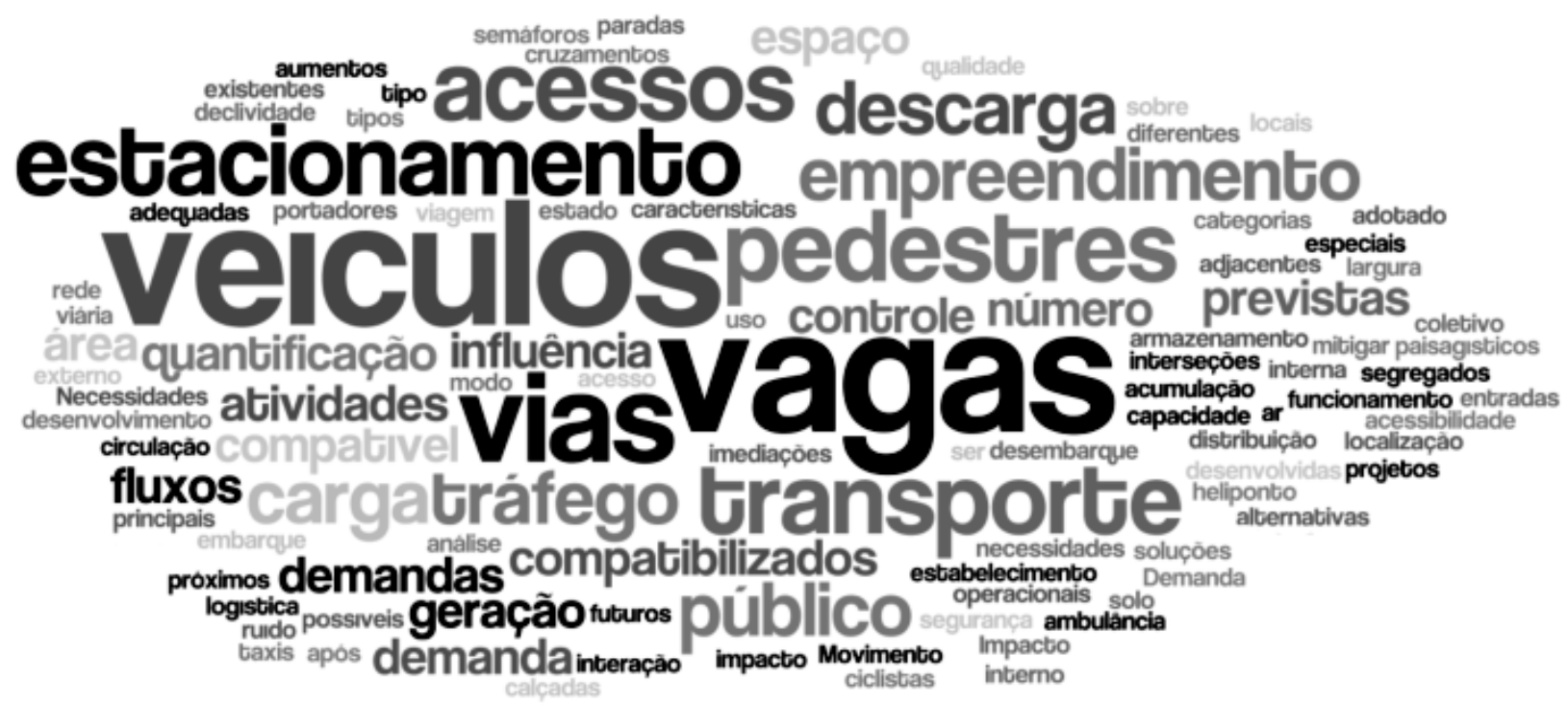

Figura 1 - Nuvem de palavras sobre textos de processos de licenciamento

\section{MEDIDAS DE MOBILIDADE URBANA SUSTENTÁVEL (MMUS)}

Inicialmente, são sugeridas duas questões: o que é mobilidade urbana? E o que é mobilidade urbana sustentável?

Segundo o Caderno de Referência para Elaboração de Plano de Mobilidade Urbana (PlanMob), o termo mobilidade urbana traz em si uma mudança de paradigma, uma nova forma de tratar o que tradicionalmente era visto de forma isolada: trânsito, logística, infraestrutura viária. Mobilidade, além de transporte, agrega uma visão ampla sobre a movimentação de pessoas e bens na cidade, chamando à responsabilidade os polos geradores de viagens ao reunir, no seu conceito, "todos os modos e todos os elementos que produzem as necessidades desses deslocamentos" (Ministério das Cidades, 2007). São muitas as iniciativas governamentais e acadêmicas acerca deste tema. No âmbito federal, o Ministério das Cidades, tem apresentado diversas publicações sobre o assunto dentro dessa nova esfera conceitual da mobilidade multimodal, democrática e sustentável, a exemplo dos Cadernos MCidades e da Política Nacional de Mobilidade Urbana Sustentável.

A mobilidade urbana sustentável pode ser definida como o resultado de um conjunto de políticas de transporte e circulação que visa proporcionar o acesso amplo e democrático ao espaço urbano, através da priorização dos modos nãomotorizados e coletivos de transporte de forma efetiva, integrada, que não gere segregações espaciais, socialmente inclusiva e ecologicamente sustentável. Ou seja: baseada nas pessoas e não nos veículos. Segundo o Ministério das Cidades (2004) as principais formas de promover a Mobilidade Urbana Sustentável são:

- Desestimular o uso intensivo do transporte particular;

- Levar em conta o planejamento integrado do transporte e uso do solo;

- Reduzir o consumo de energia e o uso de energia alternativa nos transportes coletivos;

- Diversificar as opções de transporte levando-se em consideração a intermodalidade;

- Reduzir os impactos ambientais.

\subsection{Referencial teórico para a proposição de MMUS}

A base primordial para a proposição das MMUS são os princípios e diretrizes apresentados por documentos oficiais brasileiros, como a Política Nacional de Mobilidade Urbana Sustentável - PNMUS, o Caderno para elaboração Plano 
Diretor de Transportes e da Mobilidade - PlanMob, o Programa Brasileiro de Acessibilidade Urbana e a Lei $n^{\circ}$ 12.587:2012, que institui as diretrizes para a PNMUS. Todos esses documentos acordam a mobilidade urbana sustentável como um objetivo firmado pelo país e definem princípios e diretrizes para alcançá-la. Ainda bastante generalistas, contudo abrangentes, estes princípios e diretrizes são as bases que norteiam a seleção de parâmetros para a proposição das medidas.

No contexto acadêmico, as referências basilares utilizadas para auxiliar a proposição das medidas de mobilidade desta pesquisa foram trabalhos que se dedicaram a estabelecer e aprimorar fatores condicionantes da mobilidade urbana sustentável como Costa (2008), que desenvolveu um Índice de Mobilidade Urbana Sustentável (IMUS) com ampla base em referências nacionais e internacionais, e Santos (2009), que fez uma aplicação desses indicadores na cidade do Salvador. Foram acrescentados ainda os trabalhos que compartilham o tema da mobilidade sustentável com os Polos Geradores de Viagens, traçando relações importantes entre transporte e uso do solo, como Moura (2010). Mancini e Silva (2010) fazem uma aplicação do IMUS de Costa (2008) sugerindo variáveis de possível impacto sobre o modelo de geração de viagens e propõem ações para promover a Geração de Viagens Sustentáveis (GVS) - termo apresentado pelos autores para definir viagens notadamente interessantes para serem realizadas por meios de transporte coletivo ou não motorizados (a pé e bicicleta). O estudo sugere que é possível melhorar o IMUS em cerca de $24 \%$ com ações de mínimo e médios graus de dificuldade a partir de ações de conscientização dos cidadãos, formação de técnicos e gestores, melhorias na sinalização viária e das calçadas e o incentivo ao uso do transporte público e dos modos não motorizados - sobretudo em atividades rotineiras como estudo e trabalho.

A partir de tais adaptações do espaço urbano e com a mudança no padrão de geração de viagens, não faz sentido que os PGV continuem provendo espaços aptos apenas para receber viagens de automóveis particulares. Como fora abordado na introdução, na fase projetual são estudadas demandas de viagens apenas para automóveis, porém a insustentabilidade dessas ações, sobretudo pela ocupação demasiada de espaço, deve ser incrementada por estudos de demanda por outros modos mais sustentáveis, incentivadas por provisão de infraestruturas como facilidade de acesso aos corredores de transportes coletivos, bicicletários e melhores calçadas. Isso possibilitaria a diversificação modal e um melhor aproveitamento do espaço urbano, sobretudo em espaços ligados a atividades rotineiras, tais como estudo e trabalho, dispensando a ocupação de grandes áreas destinadas a bolsões de estacionamentos em áreas centrais e em grandes empreendimentos urbanos. (Mancini e Silva, 2010)

O estudo de Mancini e Silva (2010) traz como conclusão que a maior parte das ações de influência direta sobre a geração de viagens sustentáveis $(50 \%)$ é considerada de grande dificuldade e estão voltadas a alterações nos lotes privados e sua relação com o espaço público, à integração dos modos e ao incentivo aos modos coletivos e não motorizados. Os autores ressaltam que as ações que competem também a mudanças nos lotes privados são de difícil implantação, pois não dependem somente da gestão pública, mas da atuação dos cidadãos. Desta forma, a proposta das Medidas de Mobilidade Urbana Sustentável se encaixaria dentre as ações grande dificuldade, pois em sua maioria as MMUS são direcionadas ao lote privado e sua relação com o espaço público. No entanto, elas seriam consideradas, também, como ações de influência direta sobre a geração de viagens sustentáveis, e uma vez incorporadas aos processos de licenciamento, seus impactos positivos seriam potencialmente eficazes.

\subsection{Parâmetros acionáveis para composição das MMUS}

Um princípio fundamental para a composição das MMUS é que elas sejam acionáveis. Isto é: que possam ser aplicadas no campo da prática facilmente, originando uma ação. Para isso são necessárias informações que auxiliem diretamente na tomada de decisões - uma condição atualmente, escassa na literatura nacional. Algumas referências acadêmicas, contudo, apesar de não colocarem suas condicionantes em forma de ação, permitem uma adaptação para formar proposições acionáveis a partir de seu texto original, como é o caso dos trabalhos de Schützer (2010) e Moura (2010). De forma complementar, nesta pesquisa foram contemplados parâmetros internacionais voltados ao estímulo da mobilidade urbana sus- 
tentável presentes em relatórios científicos a exemplo do estudo de Khattak e Stone (2004), que investiga a relação entre padrões de viagens e características tipológicas do lugar ao comparar duas unidades de vizinhança com desenho urbano e arquitetônico distintos; e, também em manuais técnicos como ITE (2010), que fornece diretrizes para elaboração de projetos de vias urbanas caminháveis.

A partir dessas premissas pode-se, então, conceituar que as MMUA são medidas acionáveis adaptadas da literatura e alinhadas com os princípios de mobilidade urbana sugeridas no meio acadêmico e recomendadas em documentos federais, como a Política Nacional de Mobilidade Urbana Sustentável.

Uso misto, compacidade na disposição das atividades, fachadas votadas para a rua e calçadas largas são atributos enfaticamente ressaltados por Khattak e Stone (2004) como estimuladores de viagens internas à vizinhança ao configurar um desenho urbano amigável ao pedestre. A redução das distâncias associada à segurança nas ruas, a um cenário agradável e a uma melhor qualidade do ar local são fatores que também cooperam para que uma parte destas viagens, ora feitas pelo automóvel, sejam substituídas pela caminhada. Como contraponto, os autores tomam como exemplo uma vizinhança de tipologia denominada "convencional", que se caracteriza por possuir as frentes residenciais afastadas da rua, calçada em apenas um dos lados, grandes áreas de garagem, ruas sem saída etc.

A pesquisa de Khattak e Stone (2004) pode ser especialmente interessante para traçar analogias com os Polos Múltiplos Geradores de Viagens (PMGV), sobretudo no que concerne a viagens compartilhadas e captura de viagens internas. Cavalcante et al. (2012) conceituam os PMGV a partir da composição de edifícios com atividades integrantes que apoiam umas às outras, dentro de uma mesma vizinhança. PMGVs podem compartilhar a atração das viagens de maior distância realizadas por carros ou transporte público e, ao mesmo tempo, têm o potencial de gerar viagens internas, dentro do conjunto de polos, na escala da rua, quadra ou subcentro, com maior potencial para serem realizadas a pé.

Khattak e Stone (2004) fizeram uma comparação dos padrões de viagens de duas unidades de vizinhança - a convencional, que orienta seu traçado para satisfazer demandas do automóvel, e outra que apresenta desenho urbano amigável aos pedestres, com fachadas voltadas para a rua e calçadas largas e acessíveis. Os autores concluíram que o total de viagens é similar em ambas. Porém, a vizinhança que possui um desenho urbano amigável ao pedestre apresentou menores taxas de viagens por automóvel dentre as viagens internas. Considerando que em muitos aspectos socioeconômicos e geográficos as vizinhanças estudadas eram similares, as diferenças no padrão das viagens foram atribuídas às diferenças físicas do local, como o desenho urbano e à relação entre os lotes e o espaço público (Khattak e Stone, 2004). Essas características físicas sugerem pontos de partida para produzir proposições acionáveis para o estímulo da mobilidade sustentável.

\subsection{Seleção e proposição das MMUS}

As referências citadas nas seções anteriores, sobretudo as diretrizes provenientes de documentos de referência oficial nacional, precisam ter uma abordagem abrangente, muitas vezes sem se deter a detalhes ou exemplificações. O caráter abrangente, no entanto, pode ser um empecilho à prática. Por exemplo, há uma diretriz nacional que propõe: "reconhecer a importância do deslocamento dos pedestres" (Brasil Acessível, 2006). É uma proposição clara, que, porém, não define estratégias para atingi-la. Portanto, para cada princípio ou diretriz oriunda dos estudos pesquisados é necessário encontrar pelo menos uma medida acionável equivalente. Para este caso, por exemplo, poderia se considerar as seguintes proposições: apresentar calçadas largas, livres de obstáculos e completas, o que inclui: faixa de mobiliário, faixa de circulação livre e faixa de acesso ao lote - baseada em ITE (2010) - ou apresentar quarteirões pequenos, entre 60 e 200 metros, para promover a mobilidade dos pedestres e ciclistas - baseada em (Khattak e Stone, 2004).

Seguindo esta lógica, a partir de uma seleção de 87 proposições retiradas de trabalhos acadêmicos e técnicos realizou-se a verificação da compatibilidade com os princípios nacionais de mobilidade urbana sustentável. Em seguida, fezse uma triagem, identificando proposições similares e somando pontos complementares. Padronizou-se, então, todas as proposições para uma escrita em forma de ação, começando sempre com o verbo no infinitivo. $\mathrm{O}$ resultado deste processo é um elenco de 37 proposições acionáveis que, en- 
fim, configuram-se como as medidas propriamente ditas: Medidas de Mobilidade Urbana Sustentável (MMUS).

Assim como realizado com o conteúdo textual dos processos de licenciamento, o texto das MMUS foi submetido a uma visualização gráfica (nuvem de palavras) onde sobressaem em maior fonte os termos que apareceram mais vezes no conteúdo. A Figura 2 demonstra em destaque os termos das MMUS com maior frequência: "calçada" e "pedestre". Isto é: se comparadas esta nuvem de palavras com a dos processos de licenciamento (Figura 1), percebe-se uma grande divergência de pontos de vista. Mais do que isso, evidencia-se a urgência da revisão dos processos de licenciamento atuais.

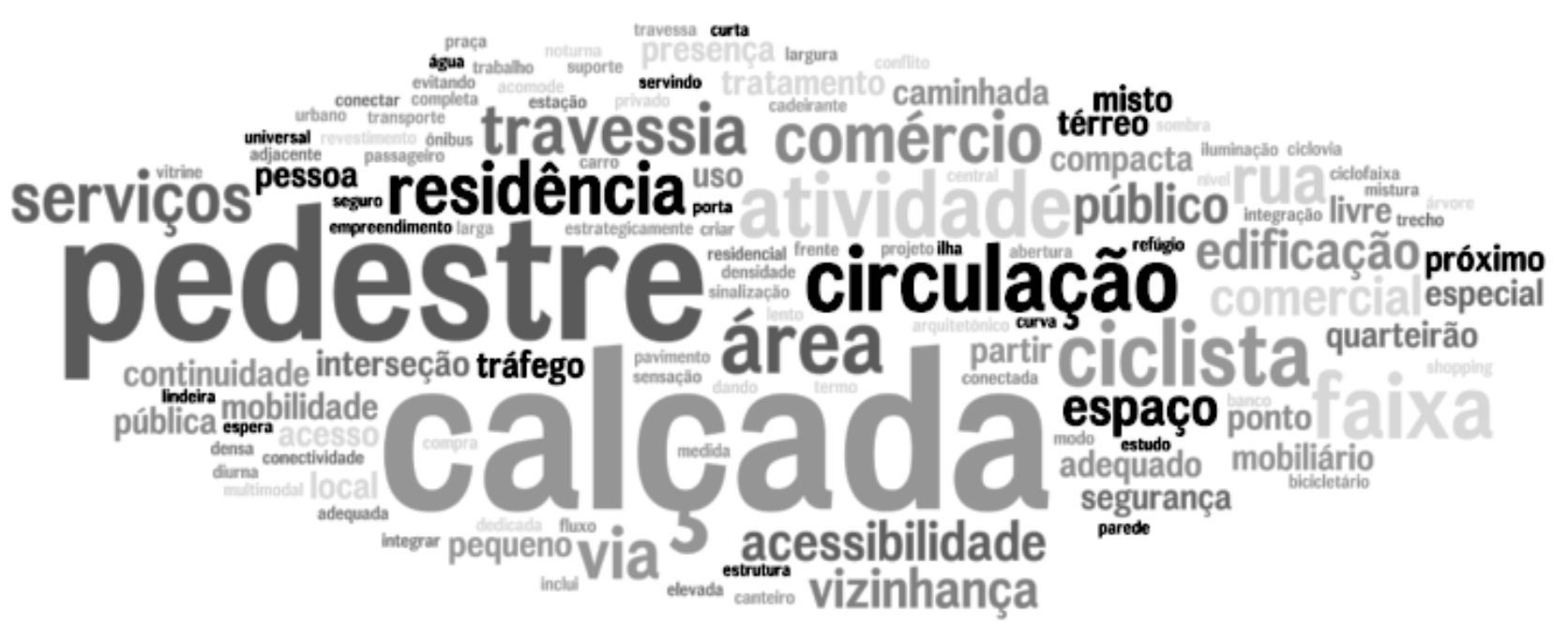

Figura 2 - Nuvem de palavras sobre o texto das 37 Medidas de Mobilidade Urbana Sustentável

\section{MMUS APLICADAS A PGVS: VALIDAÇÃO POR ESPECIALISTAS}

As Medidas de Mobilidade Urbana Sustentável (MMUS) podem ser trabalhadas sob diversas perspectivas e finalidades. A premissa inicial para a seleção deste primeiro corpo de 37 medidas é que elas fossem passíveis de aplicação ao licenciamento de PGVs. No entanto, para sua validação, fez-se necessária uma pesquisa com especialistas. Para isto, decidiu-se empregar o método de eliciação de opiniões de especialistas proposto por Cooke (1991). Neste método, são consultadas pessoas com experiência e credibilidade em um tema relevante a determinada pesquisa com a finalidade de apoiar a tomada de decisões ou elucidar questões de pesquisa. $\mathrm{O}$ método descreve quatro etapas de planejamento e execução do estudo: 1) seleção de proposições; 2) seleção de especialistas; 3) eliciação das opiniões de especialistas e 4) agregação das opiniões (Cooke, 1991). No caso deste trabalho, as opiniões dos especialistas foram empregadas, sobretudo para classificar Medidas de Mobilidade Urbana Sustentável conforme a sua aplicabilidade ao processo de licenciamento de PGVs.

\subsection{Planejamento e execução do estudo}

O estudo foi planejado e executado seguindo as quatro etapas descritas por Cooke (1991). A primeira etapa, seleção de proposições, consistiu em identificar medidas de mobilidade urbana sustentável com possibilidade de serem aplicáveis ao processo de licenciamento de PGVs. O elenco das medidas para verificação são as Medidas de Mobilidade Urbana Sustentável (MMUS). Na segunda etapa, seleção de especialistas, foram identificados e selecionados pesquisadores e profissionais que trabalham com transportes e polos geradores de viagens. No âmbito nacional, foram contatados pesquisadores que fazem parte da Rede Ibero-americana de Estudo em Polos Geradores de Viagens (Rede PGV, 2014). No âmbito local, foram contatados professores da área de mobilidade e urbanismo, profissionais que trabalham com estudo de impacto de grandes empreendimentos e profissionais da Prefeitura de Salvador que atuam no órgão municipal responsável por licenciamento. Todos os especialistas foram conta- 
tados por e-mail e, no caso de especialistas locais, alguns contatos foram reforçados por telefone. A terceira etapa, eliciação das opiniões dos especialistas, poderia ter sido realizada de diversas formas, incluindo entrevistas, discussões em grupo e aplicação de questionários. Dada a objetividade da pesquisa, optou-se por utilizar um questionário no qual os especialistas foram instruídos a marcar as medidas que consideravam relevantes para a mobilidade urbana sustentável e que devem ser contempladas na apreciação de projetos em processos de licenciamento de Polos Geradores de Viagens sob ônus do empreendedor. Foram acrescentadas ao questionário algumas perguntas que serviam para caracterizar os especialistas de acordo com sua localização, experiência e familiaridade com os temas mobilidade e PGV. O questionário foi publicado online, de forma que especialistas de diversas regiões do Brasil puderam responder convenientemente às questões. Foi estabelecida uma data limite para submissão de respostas que comporiam as análises, dando aos respondentes um período de duas semanas. Para a agregação das opiniões, quarta etapa do estudo, as respostas foram agregadas em um valor que possibilitasse medir o consenso dos especialistas sobre determinada questão.

\subsection{Sistema de pesquisa online}

$\mathrm{O}$ que possibilitou a realização da pesquisa com especialistas de todo o país em um curto espaço de tempo e sem custos foi o sistema gratuito de questionário online Google Spreadsheet. O sistema de criação, edição e síntese de questionários é acessível através de qualquer conta de e-mail Google. Cada questionário é uma página com um link próprio, que pode ser pública ou aberta apenas para convidados. Dentre as opções de formato de questão oferecidas, neste questionário utilizouse principalmente o formato checkboxes, ou caixas de validação - uma para cada medida de mobilidade urbana sustentável proposta. Foram também utilizados, para questões de perfil do especialista, outros formatos de questão: caixa de texto curto, caixa de texto longo, múltipla escolha, escala e matriz. Apesar de o próprio sistema online oferecer um resumo gráfico das respostas, optou-se por exportar a planilha gerada e processar os dados no software Excel, que possui opções para a customização dos gráficos. O questionário online está permanentemente acessível e aberto a respostas através do link: bit.ly/oOqd8Q.

\subsection{População e amostra}

O questionário foi enviado para uma lista de 198 endereços de e-mail válidos de especialistas, dentre pesquisadores e profissionais da área de licenciamento. O número exato de especialistas consultados é incerto, podendo ser inferior, uma vez que alguns especialistas da Rede PGV podem ter mais de um endereço de e-mail cadastrado. $\mathrm{Pa}$ ra fins de cálculo, a população considerada foi de 198 especialistas, dos quais foram recebidas, dentro do prazo, 30 respostas (amostra) - o que representa uma taxa de resposta de cerca de $15 \%$.

Os participantes foram caracterizados de acordo com sua localização, formação, familiaridade com os temas e experiência. Tais informações foram declaradas pelos próprios participantes ao responder o questionário. $\mathrm{O}$ questionário foi respondido por especialistas de 4 das 5 macrorregiões brasileiras (Norte, Nordeste, CentroOeste e Sudeste), e por um especialista de Portugal. As unidades federativas mais bem representadas foram Bahia e Rio de Janeiro, com $20 \%$ cada. Os participantes possuem alto nível de formação - $80 \%$ possuem pós-graduação, sendo $50 \%$ mestres, $20 \%$ doutores e $10 \%$ especialistas. Uma parte significativa dos participantes (40\%) é professor. A maior parte dos participantes (60\%) possui experiência prática e acadêmica com o tema e os $40 \%$ restantes se dividem entre especialistas com experiência somente acadêmica (27\%) e especialistas com experiência somente prática (13\%). Com relação à participação na Rede PGV, a amostra se mostrou bastante equilibrada, com $53 \%$ dos participantes fazendo parte dela.

Os especialistas foram consultados sobre a familiaridade com os temas Mobilidade Urbana Sustentável e Polos Geradores de Viagens. A maioria dos especialistas declarou possuir familiaridade "boa" ou "muito boa" com o tema Mobilidade Urbana Sustentável (93\%), com o tema Polos Geradores de Viagens (73\%) e com a união dos dois temas $(83 \%)$. Neste último item, há predominância da resposta "boa" em detrimento da resposta "muito boa". Com relação à experiência, $70 \%$ dos especialistas declararam ter até 10 anos de trabalho com os temas relacionados à pesquisa; destes, $53 \%$ possuem até 5 anos de trabalho. Os demais $30 \%$ trabalham com pelo menos um dos temas há no mínimo 10 e no máximo 30 anos. Metade dos participantes declarou já ter participado de processos de licenciamento de PGVs. Dentre estes, $40 \%$ participam, frequentemente, de 
tais processos, enquanto $60 \%$ participam eventualmente.

\subsection{Validação das MMUS para o licenciamento de PGVs: avaliação quantitativa}

No questionário foi solicitado que o participante assinalasse todas as alternativas que, em sua opinião, fossem relevantes para a mobilidade urbana sustentável e devessem ser contempladas na apreciação de projetos em processos de licenciamento de Polos Geradores de Viagens sob ônus do empreendedor. Para fins de organização, as 37 MMUS foram dispostas em nove categorias que se aproximam de classificações utilizadas em literatura internacional (Complete Streets, 2014).

Das cinco medidas propostas na categoria uso do solo, diversidade e disposição de atividades, três tiveram a aprovação de pelo menos metade dos especialistas, enquanto duas tiveram entre $23 \%$ e $33 \%$ dos votos. A medida mais bem avaliada foi "Promover atividades comerciais a uma curta distância de caminhada das residências para que a maioria das compras possam ser feitas na vizinhança".

$\mathrm{Na}$ categoria de fachadas e segurança, as opiniões foram divididas. As três medidas apresentadas tiveram entre $50 \%$ e $60 \%$ de aprovação, sendo mais bem votada a medida "Estimular a presença dos 'olhos da rua' (pessoas de residências e pontos comerciais avistando a rua, aumentando a sensação de segurança)".

$\mathrm{Na}$ categoria de calçadas foram encontradas as medidas com maior aprovação (97\%): "Promover acessibilidade para pessoas com necessidades especiais (Acessibilidade Universal)" e "Apresentar calçadas largas, livres de obstáculos e completas, o que inclui: faixa de mobiliário, faixa de circulação livre e faixa de acesso ao lote". As demais medidas apresentaram pelo menos $80 \%$ de aprovação, exceto a medida "Apresentar inclinação adequada do corte da calçada, para não empoçar água da chuva", que obteve $60 \%$ de avaliações positivas.

Com relação à travessia de pedestres, a medida mais votada $(90 \%)$ foi "Promover sinali- zação reforçada quanto à presença de pedestres e ciclistas, em especial nas regiões de conflito como travessias e interseções". As demais medidas tiveram aprovação entre $50 \%$ e $57 \%$.

Com relação à urbanização integrada e espaços de convivência, as medidas mais votadas foram "Promover espaços públicos no entorno de equipamentos de comércio e serviços" e "Permitir interação dos espaços públicos com os privados", cada uma com $77 \%$ de aprovação.

Sobre fatores de escala e desenho urbano, a grande maioria concordou com a relevância de se "Promover a conectividade das ruas e espaços de circulação" (93\%). As demais medidas, que versam sobre quarteirões pequenos e mistura de densidades, foram mais polêmicas, com $50 \%$ a $53 \%$ de aprovação.

Para as medidas relacionadas ao sistema viário do entorno, foi obtida aprovação entre $50 \%$ e $73 \%$. As medidas mais populares foram "Implantar medidas de Moderação de Tráfego" (73\%) e "Conceber vias para servirem às atividades geradas pelo contexto adjacente (comércio, serviços) em termos de mobilidade, segurança e acessibilidade" $(70 \%)$.

As medidas relacionadas ao transporte cicloviário se mostraram bastante populares, obtendo de $70 \%$ a $93 \%$ de aprovação. Destaca-se "Implementar ciclofaixas ou ciclovias", com 93\%.

Por fim, com relação a garagens e estacionamentos públicos, a aprovação foi entre $10 \%$, com a medida "Promover estacionamento ao longo da via (...)", e 90\%, com a medida "Prever tratamento adequado e seguro ao pedestre nas entradas de garagem". As avaliações para esta categoria foram mais dispersas que as outras categorias analisadas.

A Tabela 1 apresenta as Medidas de Mobilidade Urbana Sustentável (MMUS) e suas avaliações por parte dos especialistas entrevistados. Dele pode-se constatar que 34 das 37 medidas (89\% do total) possuem aprovação igual ou superior a $50 \%$, o que mostra a relevância do conjunto de medidas propostas segundo os especialistas. $\mathrm{O}$ percentual médio de aprovação é de $69 \%$.

Tabela 1 - Medidas de Mobilidade Urbana Sustentável (MMUS)

(continua)

\begin{tabular}{llc}
\hline Categoria & \multicolumn{1}{c}{ MMUS } & Aprovação (\%) \\
\hline $\begin{array}{l}\text { Uso do solo, } \\
\text { diversidade } e\end{array}$ & $\begin{array}{l}\text { Apresentar tipos do uso misto que gerem circulação de pedestres, próximos um do outro, esti- } \\
\text { mulando atividade diurna e noturna. (ITE, 2010) }\end{array}$ & 80 \\
\cline { 2 - 3 } $\begin{array}{l}\text { disposição das } \\
\text { atividades }\end{array}$ & $\begin{array}{l}\text { Dispor atividades de forma compacta, densa, compatibilizando residências, comércio e serviços } \\
\text { numa área de 200 x 200 metros. (Khattak e Stone, 2004) }\end{array}$ & 23
\end{tabular}


Tabela 1 - Medidas de Mobilidade Urbana Sustentável (MMUS)

(conclusão)

Categoria

MMUS

Aprovação (\%)

Uso do solo, diversidade e disposição das atividades

Promover e conectar residências aos locais de trabalho e estudo na vizinhança. (Khattak e Sto-

50

ne, 2004)

Promover atividades comerciais a uma curta distância de caminhada das residências para que a

33

maioria das compras possam ser feitas na vizinhança. (Schützer, 2010)

Fachadas e

Apresentar fachadas das edificações de frente para a rua com abertura

segurança

estacionamento ou recuo entre oclaça sem

2004)

Apresentar projeto arquitetônico sem paredes cegas no pavimento térreo, com janelas, vitrines e

portas voltadas para a calçada evitando trechos mortos. (Planarq, 2010; ITE, 2010)

Estimular a presença dos "olhos da rua" (pessoas de residências e pontos comerciais avistando

a rua, aumentando a sensação de segurança). (Schützer, 2010)

Calçadas Apresentar calçadas largas, livres de obstáculos e completas, o que inclui: faixa de mobiliário,

faixa de circulação livre e faixa de acesso ao lote. (ITE, 2010; Moura, 2010)

Prever aumento da largura das calçadas próximo a pontos de ônibus, estações e áreas de

grande fluxo, como no acesso a shopping centers. (ITE, 2010; Moura, 2010)

Indicar revestimento adequado para a calçada. (Moura, 2010)

Promover acessibilidade para pessoas com necessidades especiais (Acessibilidade Universal).

(ITE, 2010; Moura, 2010)

Apresentar inclinação adequada do corte da calçada, para não empoçar água da chuva. (Moura,

2010)

Apresentar continuidade das calçadas com faixas de travessia e integrar as vias de pedestres

com a vizinhança. (Moura, 2010; Urplan, 2010)

Promover estrutura nas calçadas para passageiros nos locais de espera do transporte público,

tais como bancos, árvores que provejam sombra etc. (ITE, 2010)

Promover iluminação dedicada às calçadas e áreas do pedestre. (ITE, 2010)

Fazer a manutenção das calçadas. (MOURA, 2010).

Travessias de pedestres

Prezar pela redução da quantidade de faixas nas travessias através de ilhas de refúgio de pe-

destre, canteiros centrais e curvas à direita canalizadas. (ITE, 2010)

Promover sinalização reforçada quanto à presença de pedestres e ciclistas, em especial nas re-

giões de conflito como travessias e interseções. (ITE, 2010)

Prever travessia de pedestres elevada, no nível da calçada e com pavimentação diferenciada. (ITE, 2010)

\begin{tabular}{llll}
\hline $\begin{array}{l}\text { Urbanização } \\
\text { integrada- es- }\end{array}$ & $\begin{array}{l}\text { Promover espaços públicos no entorno de equipamentos de comércio e serviços. (Planarq, } \\
\text { paços de con- }\end{array}$ & 77 \\
\cline { 2 - 4 } \begin{tabular}{l} 
vivência \\
\cline { 2 - 4 }
\end{tabular} & Tornar públicas áreas comuns do empreendimento, como praças e parques. (Planarq, 2010) & 50 \\
\cline { 2 - 4 } & Permitir interação dos espaços públicos com os privados. (Planarq, 2010) & 77
\end{tabular}

vivência

Permitir interação dos espaços públicos com os privados. (Planarq, 2010)

\begin{tabular}{|c|c|c|}
\hline \multirow{3}{*}{$\begin{array}{l}\text { Desenho urba- } \\
\text { no - fatores de } \\
\text { escala }\end{array}$} & $\begin{array}{l}\text { Apresentar quarteirões pequenos, entre } 60 \text { e } 200 \text { metros, para melhorar a mobilidade para pe- } \\
\text { destres e ciclistas. (Khattak e Stone, 2004) }\end{array}$ & 53 \\
\hline & $\begin{array}{l}\text { Apresentar mistura de densidades, incluindo edificações relativamente compactas (residenciais } \\
\text { e comerciais). (ITE, 2010) }\end{array}$ & 50 \\
\hline & $\begin{array}{l}\text { Promover a conectividade das ruas e espaços de circulação. (Khattak e Stone, 2004; Schützer, } \\
\text { 2010) }\end{array}$ & 93 \\
\hline \multirow[t]{4}{*}{$\begin{array}{l}\text { Sistema viário } \\
\text { do entorno }\end{array}$} & $\begin{array}{l}\text { Projetar a via para que ela acomode tráfego lento, pedestres, ciclistas e cadeirantes. (ITE, 2010; } \\
\text { Khattak e Stone, 2004) }\end{array}$ & 50 \\
\hline & $\begin{array}{l}\text { Apresentar uma rede de circulação multimodal altamente conectada a partir de quarteirões pe- } \\
\text { quenos. (ITE, 2010) }\end{array}$ & 50 \\
\hline & $\begin{array}{l}\text { Conceber vias para servirem às atividades geradas pelo contexto adjacente (comércio, serviços) } \\
\text { em termos de mobilidade, segurança e acessibilidade. (ITE, 2010) }\end{array}$ & 70 \\
\hline & Implantar medidas de Moderação de Tráfego. (Planarq, 2010) & 73 \\
\hline \multirow{4}{*}{$\begin{array}{l}\text { Transporte ci- } \\
\text { cloviário }\end{array}$} & Implementar ciclofaixas ou ciclovias. (ITE, 2010) & 93 \\
\hline & Promover tratamento para bicicletas em interseções. (ITE, 2010) & 70 \\
\hline & $\begin{array}{l}\text { Promover continuidade das áreas destinadas à circulação de ciclistas e integração entre este e } \\
\text { outros modos. (ITE, 2010) }\end{array}$ & 83 \\
\hline & Prover mobiliário urbano de apoio ao ciclista (bicicletários). (Moura, 2010) & 87 \\
\hline \multirow{3}{*}{$\begin{array}{l}\text { Garagens e es- } \\
\text { taciona- } \\
\text { mentos públi- } \\
\text { cos }\end{array}$} & Prever tratamento adequado e seguro ao pedestre nas entradas de garagem. (Moura, 2010) & 90 \\
\hline & Promover estacionamentos que encorajem estrategicamente a caminhada. (ITE, 2010) & 63 \\
\hline & $\begin{array}{l}\text { Promover estacionamento ao longo da via (dando suporte às atividades lindeiras; atuando na } \\
\text { redução da velocidade dos carros e servindo de barreira de proteção para o pedestre). (ITE, } \\
2010 \text { ) }\end{array}$ & 10 \\
\hline
\end{tabular}

\subsection{Validação das MMUS para o licenciamento de PGVs: avaliação qualitativa}

Foi deixado um espaço no questionário para que os participantes pudessem comentar e opinar livremente sobre as medidas, sobre o tema de pesquisa e sobre o questionário. Para analisar as respostas, foram empregados métodos sistemáticos de análise qualitativa. Em particular, foi reali- 
zado o procedimento de codificação aberta dos dados textuais (Creswell, 1998). Neste método, são anotados os conceitos que emergem de cada resposta. À medida que mais respostas são codificadas, podem surgir novos conceitos, bem como conceitos podem ser renomeados, modificados ou unidos, demandando que as respostas anteriores sejam analisadas novamente. Após realizar a codificação aberta dos dados, os conceitos foram filtrados de acordo com a relevância para esta pesquisa. A seguir são apresentados os conceitos relevantes contidos nos comentários dos especialistas, juntamente com citações de alguns trechos.

- Importância do tema. Alguns especialistas ratificaram a importância do tema da pesquisa "Excelente tema"; "O tema é extremamente importante".

- Importância das medidas. Embora a importância das medidas tenha sido avaliada quantitativamente em uma das perguntas do questionário, ela foi reforçada nos comentários - “(...) todas as sugestões eram importantes".

- Importância da pesquisa. A pesquisa em si foi considerada importante e com possibilidade de influenciar a prática — "Tem muito a contribuir com a elaboração de projetos de PGVs"; "Espero que as suas sugestões (...) possam se tornar referência prática"; "A pesquisa é importantíssima".

- Crítica à urbanização no Brasil. Foram reconhecidos problemas nas soluções de urbanização no Brasil — "A circulação urbana é muito negligenciada durante a concepção desses projetos"; "O sistema urbano na maior parte do Brasil não foi projetado para atender o ciclista, cadeirante (...)".

- Responsabilidade do empreendedor e do município. Foi levantado um questionamento sobre os papéis dos diversos agentes de modificação do espaço urbano - "Dizer que todo e qualquer problema (...) é responsabilidade do empreendedor (...) é pensar pequeno"; "O município deveria tomar medidas mais eficazes".

- Generalidade das medidas. Foi questionada a eficácia de medidas genéricas- "Algumas medidas são genéricas, (...) impossibilitando a opção de resposta"; "Talvez seja necessário restringir a um cenário de aplicação"; "Várias das medidas expostas, apesar de importantes, restringem (...) o desenvolvimento de um estu- do de impacto abrangente e específico para cada caso".

A partir da análise qualitativa, de forma geral, pode-se dizer que foi reforçada a importância das medidas, do tema e da pesquisa. Foram reconhecidos ainda problemas nas soluções de urbanização adotadas no Brasil. Também, levantaram-se questionamentos sobre o caráter genérico das medidas e sobre a responsabilidade de empreendedores e dos municípios.

\section{CONSIDERAÇÕES FINAIS}

A pesquisa de opinião com os especialistas para a validação das MMUS obteve resultados acima das expectativas. Foram enviadas muitas contribuições pertinentes e depoimentos que demonstraram identificação com o tema e reconhecimento da sua importância. A validação das Medidas de Mobilidade Urbana Sustentável chegou a quase $70 \%$ de aprovação média, sendo que 16 das 37 medidas foram validadas por mais de $80 \%$ da amostra. Esses dados são reforçados pelo consenso quanto à adoção desse tipo de medida no licenciamento de PGVs, considerada de extrema importância por $83 \%$ dos especialistas.

Quanto à pesquisa quantitativa, especificamente sobre a validação das MMUS, um aspecto que chamou atenção foi a alta aceitação das medidas direcionadas ao transporte não motorizado: calçadas e ao transporte cicloviário. Estes dois temas obtiveram mais de $80 \%$ de aceitação enquanto temas como "Fachada e segurança" e "Uso do solo, diversidade e disposição das atividades" ficaram abaixo dos 60\%. Considerando que medidas voltadas para o uso e ocupação do solo também têm reconhecido impacto sobre a mobilidade, uma possível interpretação para o destaque dos dois primeiros temas seria o fato de pedestre e ciclista serem objetos mais intimamente tratados na discussão da mobilidade urbana. A medida mais votada, que diz respeito à outra questão também bastante discutida nas áreas técnica e acadêmica, apoia essa hipótese: "Promover acessibilidade para pessoas com necessidades especiais (Acessibilidade Universal)", com 97\% de aprovação. É pertinente, portanto, considerar uma possível tendência na aprovação de medidas com temáticas mais amplamente difundidas (transporte não motorizado e acessibilidade universal). Essa 
análise sugere que pode haver lacunas no estudo de outros fatores que permeiam a mobilidade urbana e que precisam ser melhor explorados.

Outro ponto interessante de se observar nas análises dos comentários dos especialistas se refere a respostas à seguinte questão: "No(s) processo(s) de licenciamento dos quais participou, uma ou algumas das medidas propostas neste questionário foram contempladas?". Para esta questão não houve resposta negativa entre os especialistas que já participaram de processos de licenciamento de PGV. Todos eles responderam "Sim. Raramente." (60\%) ou "Sim. Frequentemente." (40\%). Este resultado foi inesperado se confrontado às conclusões feitas por Moreira (1997) e Marques (2010), que muito raramente encontraram análises e soluções para modos não motorizados nos relatórios de estudos de impacto que analisaram. Tal resultado pode demonstrar uma alta especialidade dos especialistas que compôs a amostra analisada ou talvez indicar que alguns dos respondentes tenham sentido constrangimento em responder "Não", mascarando dessa forma as respostas.

Quanto às análises qualitativas, há observações a serem realçadas e pontos a serem esclarecidos. Um destes pontos, que alertou para a necessidade de estabelecer uma premissa, foi colocado por dois especialistas: as medidas propostas podem assumir um caráter generalista e restringir a criatividade das soluções. Esta é de fato uma interpretação que precisa ser evitada, por isso é apropriado ressaltar que as MMUS devem servir como questões sugestivas e ilustráveis para ampliar o campo de análise, estender os alvos da percepção - e não o contrário. A escolha por propostas tão diretas se deu por considerar que havia uma lacuna na literatura, e na prática, por medidas passíveis de aplicação ao licenciamento de PGV e voltadas para a mobilidade urbana sustentável. Ressaltando, novamente: as MMUS são exemplos que podem ser tomados como norteadores para o licenciamento de PGV, mas não excluem a necessidade do desenvolvimento de estudos de impacto abrangentes e específicos para cada caso. As medidas propostas também não devem se limitar a elas mesmas. Elas devem ser adaptadas, expandidas, aperfeiçoadas. O importante é não esquecer, por exemplo, que a mobilidade dos modos não motorizados depende de intervenções específicas, e promover vagas de estacionamento - definitivamente - não é uma delas. Não será su- ficiente investir nos meios de transporte sustentáveis sem atentar para as questões do uso, ocupação e tipologia do desenho urbano. Para se chegar a uma mobilidade urbana sustentável plena, é necessário que os inícios e os fins das viagens - locais de origem e destino - sejam atraentes a estes modos e preparados para receber suas viagens com conforto e segurança.

\section{AGRADECIMENTOS}

Os autores agradecem aos revisores da Revista Transportes, que trabalharam com tanto esmero para nos ajudar a aprimorar este artigo. Agradecemos também ao Mestrado em Engenharia Ambiental Urbana da Universidade Federal da Bahia e à Fundação de Amparo à Pesquisa do Estado da Bahia pela bolsa de mestrado.

\section{REFERÊNCIAS}

Brasil (2012) Lei $n^{o}$ 12.587, de 3 de janeiro de 2012. Diretrizes da Política Nacional de Mobilidade Urbana. Brasília-DF.

Brasil Acessível (2006) Caderno 2 - Boas Práticas em Acessibilidade. Ministério das Cidades. Brasília-DF.

Cavalcante, A. P. H.; Freitas, I. M. D. P; Delgado, J. P. M.; Goldner, L. G.(2012) Polos de Uso Misto e Polos de Uso Múltiplo. In: Portugal, L. S. (org.) Polos Geradores de Viagens orientados à qualidade de vida e ambiental: modelos e taxas de geração de viagens. Interciência. Rio de Janeiro, RJ.

Complete Streets (2014) National Complete Streets Coalition. Smart Growth America. Site: www.smartgrowthamerica.org/complete-streets. Acessado em $31 / 03 / 2014$

Cooke, R. M. (1991) Experts in Uncertainty: Opinion and Subjective Probability in Science. New York.

Costa, M. D. S. (2008) Um índice de mobilidade urbana sustentável. Escola de Engenharia de São Carlos - USP. São Carlos.

Creswell, J. (1998) Qualitative inquiry and research design: Choosing among five traditions. Thousand Oaks, California.

ITE (2010) Design Walkable Urban Thoroughfares - A Context Sensitive Approach. Institute of Transportation Engineers and Congress for the New Urbanism. [S.1.].

Khattak, A. J.; Stone, J. (2004) Traditional Neighborhood Development - Trip Generation Study. Center for Urban \& Regional Studies. Department of City and Regional Planning University of North Carolina. USA. Carolina Transportation Program.

Mancini, M. T.; Silva, A. N. R. (2010) Padrões de geração de viagens e mobilidade urbana sustentável. Revista Transportes, XVIII, n. 1, Março 2010. 36-45.

Marques, J. D. S. (2010) Estudo de Impacto de Vizinhança: uma análise crítica feita por meio dos relatórios de impacto de vizinhança apresentados no DF. Universidade de Brasília. 
Ministério das Cidades (2004) Política Nacional de Mobilidade Urbana Sustentável. Secretaria Nacional de Transportes e Mobilidade Urbana - SeMOB. [S.1.].

Ministério das Cidades (2007) Caderno de Referência para Elaboração de Plano de Mobilidade Urbana. Secretaria Nacional de Transporte e da Mobilidade Urbana - SeMob.

Moraes, E. B. A. D. (2008) Processos de Licenciamento de Polos Geradores de Viagens: o estudo de caso do Recife-PE. Universidade Federal de Pernambuco. Recife.

Moreira, A. C. M. L. (1997) Mega-projetos \& Ambiente Urbano: uma metodologia para elaboração de relatório de impacto de vizinhança. FAAUSP. São Paulo.

Moura, M. V. D. (2010) Estudo dos impactos causados por polos geradores de viagens na circulação de pedestres. Universidade Federal de Brasília. Brasília. Dissertação de Mestrado.
Rede PGV - Rede Ibero-Americana de Estudos em PGV. PET/COPPE/UFRJ. Disponível no site: htpp://redepgv.coppe.ufrj.br. Acesso em: 27.mar.2014

Portugal, L. S.; Goldner, L. G. (2003) Estudo de Polos Geradores de Tráfego e de seus Impactos nos Sistemas Viários e de Transportes. [S.1.]: Ed. Edgard Blucher.

Santos, D.V.C. (2011) Polos Geradores de Viagens Sustentáveis: uma proposta para o licenciamento e a análise de projetos. Dissertação de Mestrado. MEAU/UFBA.

Santos, O. B. (2009) Indicadores de mobilidade urbana: uma avaliação da sustentabilidade em áreas de Salvador - Bahia. Dissertação de Mestrado. MEAU/UFBA.

Schützer, K. (2010) A percepção do pedestre sobre a qualidade da paisagem urbana. Universidade Federal de São Carlos. São Carlos 